\title{
Who is more motivated to learn? The roles of family background and teacher-student interaction in motivating student learning
}

Ran Liu ${ }^{1 *}$ (D) and Yi-Lin Chiang ${ }^{2}$

\author{
* Correspondence: ranliu@sas. \\ upenn.edu \\ ${ }^{1}$ Department of Sociology, \\ University of Pennsylvania, 3718 \\ Locus Walk, Philadelphia, PA 19104, \\ USA \\ Full list of author information is \\ available at the end of the article
}

\begin{abstract}
Scholars generally agree that family socioeconomic status significantly influences student engagement and motivation in school learning. Yet, teachers are key adults who play an equally important role in determining student experiences through daily interactions in the classroom. This study asks how family and teachers together shape student motivation to learn. Using data from the China Education Panel Survey (CEPS), we examine the roles of teachers vis-a-vis parents in fostering students' motivation to learn Math, Chinese, and English subjects. We find that both family background and student-teacher interactions are related to students' learning motivation. However, student-teacher interactions fully mediate the association of family background and student motivation to learn Math and Chinese, whereas student interest in learning English remains independently related to family background. Importantly, we show that students with strong learning motivation have high academic performance. Our findings reveal a hidden mechanism of the reproduction of class inequality through the school system and suggest that not only parents but teachers also play a nontrivial role in shaping educational inequality. We discuss the implications of our findings on educational stratification in Chinese society.
\end{abstract}

Keywords: Student motivation, Student-teacher interaction, Educational inequality, Secondary education, China

\section{Introduction}

Research on educational inequality highlights the ways through which family background shapes children's educational experiences, trajectories, and academic interests (Dumais and Ward 2010; Lareau 2011; Mok 2016; Shavit and Blossfeld 1993). Studies show that parents influence children's educational outcomes by adopting class-based patterns of parental involvement and providing cultural resources that instill educational benefits to their children (Calarco 2011; DiMaggio 1982; Lareau 2011). Another body of literature emphasizes the role of other adults, especially teachers, who shape student educational outcomes and interests in equally significant ways. For instance, student interactions with teachers in the classroom are systematically associated with varying levels of academic interest and school performance (De Boer et al. 2010; Jussim and Harber 2005; Skinner and Belmont 1993). Yet, while both family background and student-teacher interactions in the classroom individually shape students' academic interests and outcomes, the relationship between family,

(c) The Author(s). 2019 Open Access This article is distributed under the terms of the Creative Commons Attribution 4.0 International License (http://creativecommons.org/licenses/by/4.0/), which permits unrestricted use, distribution, and reproduction in any medium, provided you give appropriate credit to the original author(s) and the source, provide a link to the Creative Commons license, and indicate if changes were made. 
teachers, and students are often intertwined. By separately examining these sets of relationships, the dynamics that form patterns of students' academic motivations and educational outcomes are not entirely clear.

This study addresses the dynamic relationships of family, teachers, and students by examining how family background and student-teacher interactions simultaneously shape student motivation. We draw on data from the China Education Panel Survey (CEPS) to investigate student learning motivation in three academic subjects: Math, Chinese, and English. We separately examine the three subjects because they are likely related to the family background in different ways (we describe the relationships of each subject and family background in detail below). For the purpose of this paper, we focus on students' instrumental motivation, which is defined as their interest in learning based on conscious calculation of perceived benefits (OECD 2013). Instrumental motivation is shown to be significantly related to educational outcomes (Sewell, Haller, and Portes 1969). Our findings show that both family background and student-teacher interactions are positively related to student instrumental motivation in all three subjects. Yet, when examining these sets of relationships simultaneously, student-teacher interactions completely mediate the association between family background and student learning motivation. We also find that student-teacher interactions are stronger related to student motivation for pupils from advantaged backgrounds than those from disadvantaged ones. Furthermore, student motivation is positively associated with academic performance.

Findings in this paper carry important implications for educational inequality in the Chinese society. In terms of student motivation, whereas parents and teachers significantly shape student lives, our finding of a mediated relationship highlights the critical role of teachers vis-à-vis family background. The fact that student-teacher interactions is not only related to but also exacerbates class-based advantages in student motivation further suggests that teachers take part in the reproduction of inequality at school. Considering that student motivations are directly related to educational achievement, our findings point to student-teacher interactions in the classroom as a hidden mechanism of class-based advantage that is not fully explored.

This paper proceeds as follows. We first briefly review literature on student motivations with particular attention to differences related to family socioeconomic background and classroom interactions with teachers. We then examine the relationship between family SES, student-teacher interaction, and student motivation with data from the China Education Panel Survey (CEPS). To test our hypotheses, we decompose the findings into three analyses: (1) we assess the importance of teachers by analyzing factors that are related to positive student-teacher interactions in the classroom, (2) we investigate how family background and student-teacher interactions intertwine in shaping student motivation and pay particular attention to whether the importance of either differs by subjects, and (3) we examine the relationship between student motivation and academic performance. Finally, we discuss the theoretical and practical implications of our findings and offer suggestions that address class-based inequality in Chinese middle school classrooms.

\section{Parents, teachers, and student motivation to learn}

\section{Motivation to learn: family background and student-teacher interactions}

When examining factors related to student academic outcomes, many scholars agree that family background plays a critical role. Family background, operationalized as 
family socioeconomic status, influences children's participation in school activities, amount of resources available for children's education, school environment, and the support children receive to complete school requirements (Brunello and Checchi 2007; Calarco 2011; Chiang 2018; Entwisle and Alexander 1994; Nonoyama-Tarumi 2008; Shavit and Blossfeld 1993). In addition to providing external support to children, family background is related to children's educational outcomes through internal mechanisms. Specifically, studies show that family background is associated with children's academic learning motivations (Eccles 2007, 2009). Research finds that students' motivation to learn reflects class-based differences, such that advantaged families are able to instill high levels of learning motivation in their children by providing high levels of social-emotional support as well as class-based opportunities and resources at home (Eccles 2007, 2009). For example, children from privileged backgrounds are encouraged to value learning and therefore develop higher motivations to master academic subjects compared to their disadvantaged peers (Heckman 2008, 2011).

While many studies strongly suggest that family background is significantly related to student motivations to learn at school, some scholars suggest that motivations for academic learning are individual-based and not tightly linked with class background. These studies show that some students keenly participate in academic competition, while others are less interested in coursework (Milner 2015). Even among students from comparable family backgrounds, some are strongly motivated to pursue academic excellence, while others are more interested in non-academic activities (Gaztambide-Fernandez 2009). Furthermore, learning motivations are even a pathway for upward mobility, as disadvantaged students with high levels of motivation can obtain higher academic performance and compete with their advantaged peers (Grolnick et al. 2009; Marchant et al. 2001).

Considering the debate over the relationship between family background and student motivations, it is not entirely clear whether there is a relationship between the two in the Chinese context. Even if there were a relationship between family background and student motivation, the inconsistent findings in literature do not clearly suggest whether students from advantaged backgrounds are more or less motivated to learn compared to students from disadvantaged backgrounds. To examine whether family background is related to student motivations to learn, we first ask: (1) How is family background related to student learning motivation?

In addition to parents, teachers are also key adults who shape students' learning, particularly through classroom interactions (Cao and Chen 2009; Farmer et al. 2011; Pianta et al. 2012). Yet, depending on the type of student-teacher interaction that takes place in the classroom, interactions with teachers can be positively or negatively related to student learning motivations. Some studies find that students who develop positive relationships with teachers are strongly motivated to pursue academic excellence (Wentzel et al. 1997, 2010). Teachers also help to motivate student learning in the classroom through praises directed to the student in public, such that the student who is publicly praised often becomes and stays highly interested in coursework and performs better (Cohen and Lotan 1995; Cohen et al. 1989). On the other hand, studies show that students who are shamed by teachers in public often report lowered levels of learning motivations and have decreased levels of classroom engagement (Brophy 2013; Henderson and Dweck 1990; Reimer 1996). Taken together, literature agrees that student-teacher interactions are 
significantly related to student motivations, albeit the direction of this relationship depends on the particular interaction style.

In Chinese classrooms, teachers take the lead in guiding students' educational decisions and exam preparation. Because teachers play a particularly important role in the exam preparation process, frequent classroom interactions with teachers might be a signal of students' high levels of learning motivation. Yet, other studies suggest that student-teacher interactions in China seem to vary by school, and not by student interests or ability (Chiang 2018). We test how student-teacher relationships might be beneficial or hurtful to student learning in our second research question: (2) How is student-teacher interaction in the classroom related to student learning motivation?

While scholars agree that family and teachers are both important factors that shape student learning, the role of teachers vis-à-vis family background in shaping student motivation remains under debate. Some scholars emphasize family background by showing its larger effect on learning motivations compared to the effect of teacher-student relationships (Chirkov and Ryan 2001; Ryan et al. 1994). Others argue that teachers play an independently crucial role in students' learning process. For example, Ho and Cherng (2018) find that instead of actual parental involvement, teacher perception of parents is highly important in determining whether they agree to give the student recommendation letters. Studies based on evidence in China often support this perspective. Kipnis (2011) suggests that teachers are more important than families in fostering student motivation because students spend a significantly longer time at school; Chiang (2018) finds that parents often take a hands-off approach in children's schooling and instead rely on teachers to prepare children for exams.

Yet, the fact that teachers and family both play an independent role in shaping student learning does not exclude the possibility that one mediates the influence of the other (Sewell, Haller, and Portes 1969). A third perspective argues that interaction between teacher and family background mediates the other's influence on student motivations. Family background may determine students' interaction style and frequency of interaction with teachers. For example, parents often coach children about how to talk to teachers and will demonstrate class-based interactions styles with the teachers to gain educational benefits for their children (Calarco 2011; Hughes and Kwok 2007; Lareau 2011). Further, teachers often develop less favorable attitudes toward students from disadvantaged backgrounds, have low expectation on these students, and give these students less challenging coursework (Auwarter and Aruguete 2008; Farkas et al. 1990; Rist 1970). Additionally, teachers who believe that student's educational outcomes are primarily determined by their family background report less motivation in spending time and effort on students from disadvantaged backgrounds (Diamond et al. 2004).

The importance of teachers vis-à-vis family in motivating student learning may also differ by academic subjects. Some academic subjects may depend more on family economic and cultural capital than others (Chiang 2018; Dumais and Ward 2010; Lareau 2011). The English subject is often considered a type of class-based cultural repertoire in Chinese societies, as it instills educational benefits to students from privileged family backgrounds ( $\mathrm{Hu} 2008$; Lin 1999). In addition to English, language subjects, including Chinese, are often found to be associated with family background, whereas Math is often considered to be a type of cognitive measurement that is relatively less relevant to family background than language subjects (Saracho and Spodek 2008). These findings point to the possibility that students from different family backgrounds may be differently motivated to study English, Chinese, and 
Math. Therefore, to examine whether and how teachers facilitate students' learning motivation, it is necessary to compare how teachers across different academic subjects shape students motivation from different family backgrounds.

In short, student motivation reflects differences in class background as well as routine interactions with significant adults, but the relationship between family background, teacher-student interactions, and students' learning motivation is not entirely clear. Some studies argue that family background is crucial, others show that teachers can medicate the effect of family background on student motivations to learn. Furthermore, the relationship between family background, student-teacher interactions, and student motivations likely differs across subjects. Thus, to investigate the dynamics in the set of relationships, our third set of research questions ask: (3) Does student-teacher interaction mediate the effect of family background on students' learning motivations of different subjects?

\section{Student learning motivation and educational achievement}

Student learning motivations are important because they are positively associated with academic outcomes. Like studies elsewhere, research based on data in China shows that learning motivations and cognitive test scores are positively correlated. For example, Wang and Guthrie (2011) and a report from OECD (2013) show that Chinese students with higher learning motivations tend to have higher Math and reading scores (Wang and Guthrie 2011). However, these studies either focus on students in certain parts of China (such as Shanghai in the OECD report) or are small in the scale of survey. Considering the extent of student diversity in China, whether these findings are applicable to students in general across the nation remains to be examined.

Contextualizing the importance of learning motivations, we focus on instrumental motivation for learning because we believe this learning motivation is especially important for Chinese students. In China, where students go through intense exam selection, educational outcomes are widely believed to determine one's future status (Chiang 2018; Kipnis 2011). Parents and teachers who recognize the limitations of reliance on emotion-based, intrinsic motivations typically draw on rational, instrumental reasons when convincing teenagers to spend years to prepare for the college exam (Kipnis 2011). Further, students' external and rational motivation to learn may be susceptible to adult influence and better reflects class-based inequality in society.

In short, whether the association between instrumental motivation and student educational outcome holds as a general pattern in Chinese society remains in need of examination. Thus, our fourth research question tests the positive relationship between students' instrumental motivation and academic performances: (4) Is student's instrumental motivation to learn positively associated with student's academic performance?

\section{Data and methods}

Data

Data for this study comes from the first wave of the China Education Panel Survey (CEPS), a nationally representative survey of seventh and ninth grade students in mainland China. 
Through multi-staged stratified sampling, CEPS sampled 19,487 students in 112 schools across 28 county-level administrative units. We use the first wave of survey that administered in 2013-2014, which includes student and parent surveys. We use list-wise deletion to drop the students who did not report their learning motivation. We further excluded students who have missing information on any demographic characteristic used in the analyses. Together, less than $12 \%$ of the survey respondents were excluded. The final sample used for this study consists of 17,284 students.

\section{Measurements}

Our main outcome variable is students' self-reported learning motivation in three subjects: Math, Chinese, and English. We used three questions, "Math/Chinese/ English is highly useful for my future" as indicators for students' instrumental motivation to learn ( 1 = completely disagree; 2 = relatively disagree; 3 = relatively agree; 4 = completely agree). This set of questions is a direct measure of students' instrumental learning motivation, which focuses on perceived returns or benefits (Eccles and Wigfield 2002; Gonzalez-DeHass et al. 2005). Although this variable is an ordered one, further analysis showed that treating student motivation as a numeric or ordered variable yielded the same results. We thus present the outcomes as a continuous variable. ${ }^{1}$

Considering that literature suggests that Chinese, Math, and English subjects are differently related to family background, students from the same family background may have varying levels of motivations toward these subjects (Yong and Campbell 1995). Hence, we separately examine the three subjects to account for possible differences in the effects. To do so, we retain the subjects as separate measures in the analysis.

Family background (SES) is a composite measure that takes into account four indicators of family background. These include the highest number of years of parental education, whether the respondent has access to a computer and/or internet at home, number of books in the household, and whether the child has their own desk at home. The survey does not include information on family income or wealth. Nonetheless, the four variables present the overall status of family socioeconomic well-being because it contains traditional measures of education (parental education), as well as economic and cultural resources (desk, computer, internet access, and number of books). We use factor analysis to create a scale of family SES to combine these four variables. While the SES variable could be constructed through latent class analysis, which would transform family SES into a categorical variable, the two analytical methods yielded similar results. Since numeric variables retain more information than categorical ones do, we present the findings using family SES as a continuous variable. Furthermore, we standardized family SES to an average of 0 and standard deviation of 1 for easy interpretation.

The CEPS data contain two questions that measure student-teacher interactions: "My Math/Chinese/English teacher often asks me questions" and "My Math/Chinese/English teacher often praises me" ( $1=$ completely disagree; 2 = relatively disagree; 3 = relatively agree; 4 =completely agree). As with the case of learning motivations, students answered these questions separately for Math, Chinese, and English. Since directing questions toward and praising students are both considered 
positive types of student-teacher interactions in the classroom (Jones and Carter 2007), we created a composite variable of student-teacher interaction for by taking the sum of the answers. Further, since the level of interaction between each student and Math/Chinese/English teachers can vary, we analyze these three subjects separately.

Students' academic achievement is measured by their midterm scores in each of the three subjects. For the purpose of our study, we use cognitive test scores as a control variable for students' cognitive ability. ${ }^{2}$ We took into account the degrees of diversity of schools in a national sample by standardizing midterm scores of each subject within each cohort and school. The standardized scores have an average of 70 and standard deviation of 10. Cognitive test scores are standardized within the full sample with an average of 0 and standard deviation of 1 .

We further include several control variables of student characteristics in our analyses. We control for gender because research on Chinese students shows that girls have an advantage over boys in Chinese, Math, and English subjects (Liu 2018). Additionally, we include urban hukou, ${ }^{3}$ coresidence status with both parents and singleton status because these characteristics are associated with high academic performances in China (Poston and Falbo 1990; Tsui and Rich 2002; Zhao et al. 2014). Another factor related to student achievement is student effort, which we measure by the number of hours per week spent on homework. We additionally include ethnic background and migrant status because research shows that migrant students and ethnic minorities have lower school performance and teachers often interact with them less favorably compared to urban children (Lu and Zhou 2013; Zhao et al. 2014). Finally, we control for parent-teacher interaction because studies show that parents shape students' academic performances and learning motivation through interactions with teachers (Lareau 2011; Marcon 1999). This variable is operationalized by taking the sum of the number of times that parents and teachers initiated interactions with each other in the past semester, as reported by parents. Table 1 presents the descriptive statistics for the variables that are not standardized.

\section{Models}

We used linear regression models with school fixed effects in our analyses because students are not randomly assigned to schools. ${ }^{4}$ The clustering of students with certain characteristics in schools violates one of the basic assumptions of linear regression models, leading to biased standard errors for estimation without adjustment (Allison 2009). School-level fixed effect models are a suitable method of analysis because this model accounts for differences that are produced by school-invariant characteristics. ${ }^{5}$ The analyses include individual-level survey sampling weights to account for the survey sampling.

We present three sets of analyses. First, we test whether and how family background and student-teacher interactions are related in the Chinese middle school context. Next, we examine the ways through which family background and student-teacher interactions are associated with student motivations. We pay particular attention to the relationship between student learning motivation and the 
Table 1 Descriptive statistics of student sample $(N=17,284)$

\begin{tabular}{lll}
\hline & Mean or \% & SD \\
\hline Motivation to learn Math & 3.197 & 0.845 \\
Motivation to learn Chinese & 3.393 & 0.749 \\
Motivation to learn English & 3.235 & 0.884 \\
Student interaction with Math teacher & 5.043 & 1.640 \\
Student interaction with Chinese teacher & 5.182 & 1.595 \\
Student interaction with English teacher & 5.211 & 1.655 \\
Female & 49.4 & - \\
Migrant status & 17.7 & - \\
Ethnic minority & 8.0 & - \\
Rural hukou & 54.7 & - \\
Only child & 44.2 & - \\
Coresidence with both parents & 77.3 & - \\
Student effort & 5.585 & 4.075 \\
Frequency of parent-teacher interaction & 4.506 & 1.758 \\
\hline
\end{tabular}

interaction between family socioeconomic status and student-teacher interactions. The interaction term between family SES and student-teacher interactions allow the researchers to further examine whether the correlation between teacher-student interaction and student learning motivation vary according to student family SES. Finally, we turn attention to the significance of student learning motivations by examining the relationship between learning motivation and academic performances.

\section{Findings}

\section{Family background, student-teacher interactions, and student motivation}

We first examine the relationship between family background, student-teacher interactions, and student motivation. Table 2 presents the results from school fixed effects to predict student motivation with family background, student-teacher interaction, and their interaction terms for three academic subjects. We omit the individual control variables because our focus is on the complex relationship between family, teachers, and students.

Our findings indicate that family SES is positively correlated with students' instrumental motivations to learn. Model 1 shows that students with higher family SES tend to have higher learning motivations in all three subjects. However, the association between family SES and learning motivation is stronger in English compared to Chinese and Math: one unit increase in family SES is associated with 0.101 units increase in English learning motivation, but increases Chinese motivation by 0.069 units. The unit increase for Math motivation is even lower and at 0.046 units per unit increase in family SES. The variation observed between by subjects likely reflects the different meanings of each subject. Specifically, English reflects class-based advantage, while Math is least associated to family background among the three subjects. 


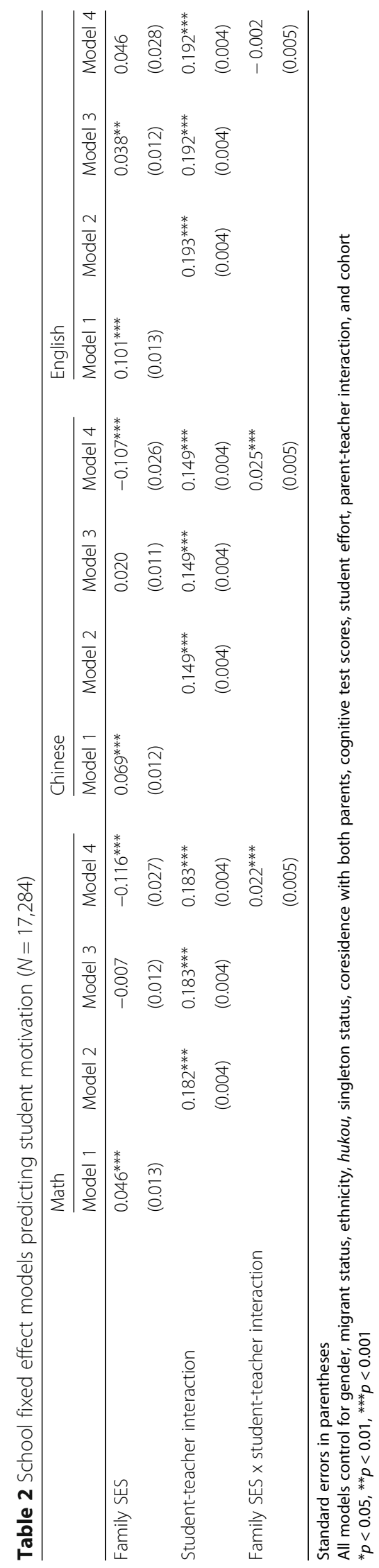


Turning attention to the relationship between student-teacher interactions and student motivation, we find that the two are also significantly correlated. Model 2 in Table 2 shows that students who have more interaction with their teachers also have higher motivation in learning across all three subjects. In particular, one unit increase in student-teacher interaction is associated with 0.182 units increase in Math learning motivation, 0.149 units increase in Chinese learning motivation, and 0.193 units increase in English learning motivation. This pattern supports the perspective that students' learning motivation is highly related to the frequency of being called on to answer questions and being praised by teachers in the classroom (De Boer et al. 2010; Jussim and Harber 2005; Skinner and Belmont 1993).

In model 3, we test the mediation effect of student-teacher interaction between family SES and student motivation by including both independent variables in the model. The results show that student-teacher interaction remains positively related to learning motivations in all three subjects after including family SES. This indicates that, for students with the same level of family SES, classroom interactions with teachers are highly important in fostering learning motivation. On the other hand, family SES is no longer significantly related to learning motivations for Math and Chinese after including both independent variables into the model. This indicates that student-teacher interactions completely mediate the association between family SES and learning motivation in these two subjects. In other words, the correlation between family SES and student learning motivation in Chinese and Math is primarily due to the correlation between family SES and teacher-student interaction.

On the other hand, student motivation in learning English remains significantly associated with both family SES and student-teacher interaction. This means even if students from different family backgrounds have the same level of interaction with their English teachers, family SES still plays a role in fostering their learning motivation. While we do not directly examine the reason for the different patterns of association across the three academic subjects, we note that English is shaped by class-based values assigned to the subject and closely related to family resources. The stronger connection between student motivations in learning English and family SES thus reflects what other studies find-that English is a type of cultural advantage enjoyed by students of privileged backgrounds in China.

To further explore the dynamics between family background, student-teacher interaction, and student learning motivation, we add an interaction term between the two independent variables in model 4 . The significantly positive interaction coefficients mean that the association between student-teacher interaction and learning motivation in Math and Chinese is stronger for students with higher family SES compared to students with lower family SES. This suggests that, for every additional unit of student-teacher interaction, the increase in high-SES students' learning motivation is larger compared to that of low-SES students.

Additional analysis shows that student-teacher interactions are significantly associated to family background, such that students from advantaged families have more interaction with teachers than their peers from disadvantaged backgrounds (see Table 4 for the relationship between family background and student-teacher interaction). Since high-SES students not only benefit more from interactions with 
teachers, but also have more interaction with teachers than their low SES counterparts, the results imply that class-based inequality is embedded in student-teacher interactions in the classroom.

To facilitate interpretation of the interaction term, we graph the results of model 4 in Fig. 1. In Fig. 1, with every unit increase of student-teacher interaction, the increase in motivation to learn Chinese and Math is greater for high-SES students than for low-SES students. Among students who rarely interact with teachers, those with low family SES are higher motivated to learn Math and Chinese than students from high family SES backgrounds. However, the class-based learning motivation becomes reversed as student-teacher interaction increases, so that among students who frequently interact with teachers, those with low family SES in fact have lower learning motivation than their high-SES counterparts.

Again, motivation to learn English shows a different pattern. In model 4, the interaction term between family SES and student-teacher interaction in English class is not statistically significant. This means that the association between family SES and student learning motivation in English does not vary by student-teacher interaction. Figure 1 shows that for both high- and low-SES students, motivation to learn English increases alongside with the frequency of student-teacher interaction. The motivation gap between high- and low-SES students remains the same across different levels of student-teacher interactions. This implies that students from different family origins similarly benefit from interacting with English teachers.

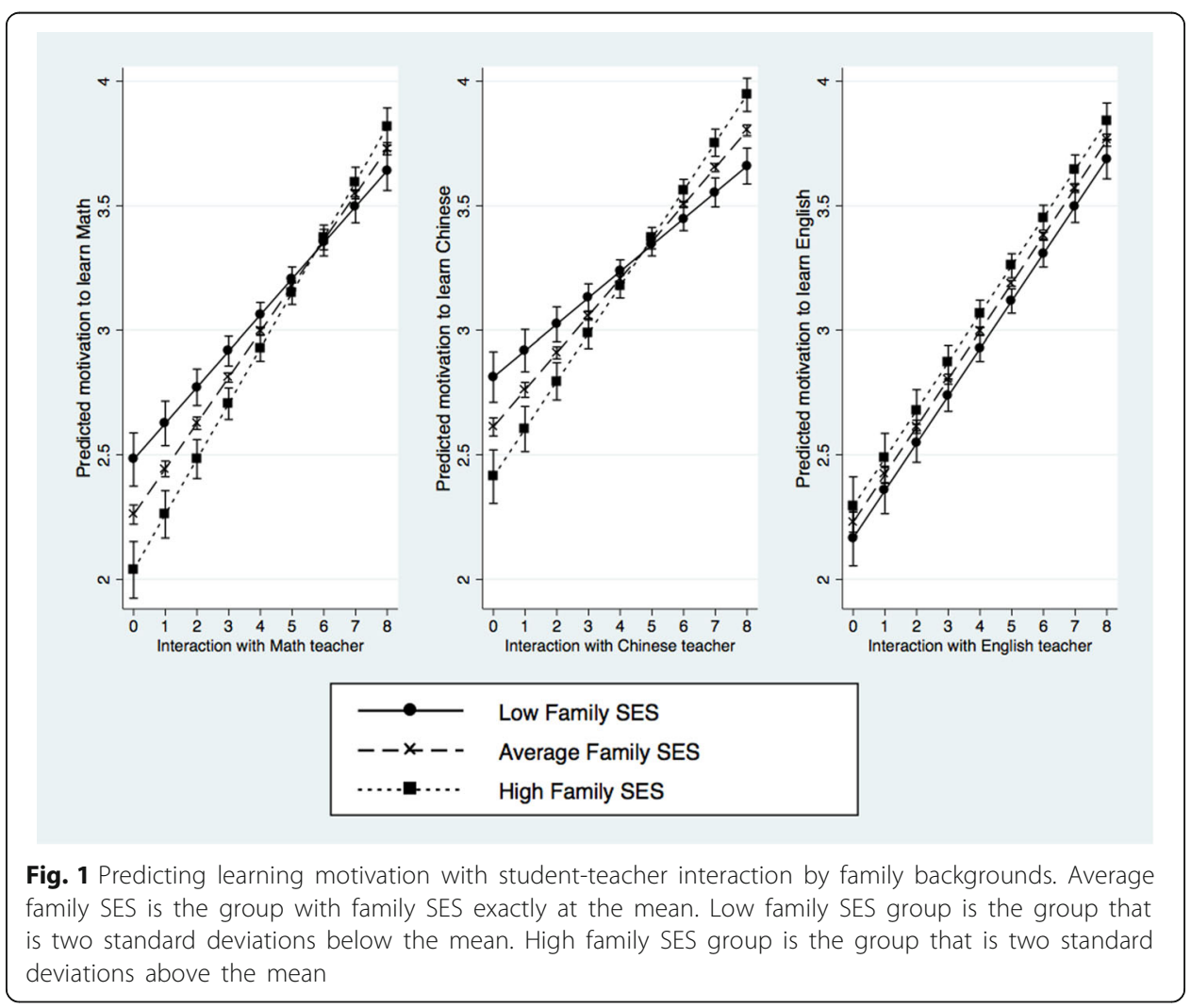




\section{Student motivation and academic achievement}

We further examine the relationship between student instrumental motivation and academic achievements in Chinese, Math, and English subjects. Results are presented in Table 3, which show that the two are positively related. Model 1 shows that student learning motivation is positively associated with student performance in all three subjects prior to controlling for family background and other demographic characteristics. We include family background and other control variables in model 2. Results in model 2 are similar to those in model 1. Students who come from privileged family backgrounds have significantly higher academic performance in all three subjects compared to students from disadvantaged family backgrounds. It should be noted that controlling for family background slightly decreases the magnitude of the association between student motivation and standardized midterm scores. However, the relationship remains significantly positive for all three subjects. Holding other control variables constant, the regression results show

Table 3 School fixed effect models predicting student performance $(N=17,284)$

\begin{tabular}{|c|c|c|c|c|c|c|}
\hline & \multicolumn{3}{|l|}{ Model 1} & \multicolumn{3}{|l|}{ Model 2} \\
\hline & Math & Chinese & English & Math & Chinese & English \\
\hline \multirow[t]{2}{*}{ Motivation } & $2.266^{* * *}$ & $1.668^{* * *}$ & $2.813^{* * *}$ & $1.708^{* * *}$ & $1.180^{* * *}$ & $1.992^{* * *}$ \\
\hline & $(0.090)$ & $(0.099)$ & $(0.085)$ & $(0.082)$ & $(0.089)$ & $(0.078)$ \\
\hline \multirow[t]{2}{*}{ Family SES } & & & & $1.005^{* * *}$ & $1.330^{* * *}$ & $1.369^{* * *}$ \\
\hline & & & & $(0.138)$ & $(0.135)$ & $(0.135)$ \\
\hline \multirow[t]{2}{*}{ Female } & & & & $1.134^{* * *}$ & $5.491^{* * *}$ & $4.961^{* * *}$ \\
\hline & & & & $(0.137)$ & $(0.135)$ & $(0.137)$ \\
\hline \multirow[t]{2}{*}{ Migrant } & & & & $0.907^{* * *}$ & $1.249^{* * *}$ & $0.615^{* *}$ \\
\hline & & & & $(0.207)$ & $(0.203)$ & $(0.203)$ \\
\hline \multirow[t]{2}{*}{ Ethnic minority } & & & & 0.009 & -0.009 & 0.176 \\
\hline & & & & $(0.356)$ & $(0.349)$ & $(0.349)$ \\
\hline \multirow[t]{2}{*}{ Rural hukou } & & & & 0.306 & 0.268 & -0.062 \\
\hline & & & & $(0.170)$ & $(0.167)$ & $(0.167)$ \\
\hline \multirow[t]{2}{*}{ Only child } & & & & $0.691^{* * *}$ & $0.342^{*}$ & $0.706^{* * *}$ \\
\hline & & & & $(0.169)$ & $(0.166)$ & $(0.166)$ \\
\hline \multirow[t]{2}{*}{ Coresidence with both parents } & & & & $0.622^{* * *}$ & $0.587^{* * *}$ & $0.436^{* *}$ \\
\hline & & & & $(0.171)$ & $(0.168)$ & $(0.168)$ \\
\hline \multirow[t]{2}{*}{ Cognitive test score } & & & & $5.226^{* * *}$ & $4.050^{* * *}$ & $4.187^{* * *}$ \\
\hline & & & & $(0.090)$ & $(0.088)$ & $(0.088)$ \\
\hline \multirow[t]{2}{*}{ Student effort } & & & & $0.082^{* * *}$ & $0.072^{* * *}$ & $0.086^{* * *}$ \\
\hline & & & & $(0.017)$ & $(0.017)$ & $(0.017)$ \\
\hline \multirow[t]{2}{*}{ Parent-teacher interaction } & & & & $-0.246^{* * *}$ & $-0.287^{* * *}$ & $-0.213^{* * *}$ \\
\hline & & & & $(0.041)$ & $(0.040)$ & $(0.040)$ \\
\hline \multirow[t]{2}{*}{ Ninth grade cohort } & $0.728^{* * *}$ & $0.349^{*}$ & $0.847^{* * *}$ & $0.431^{* *}$ & 0.077 & $0.395^{* *}$ \\
\hline & $(0.151)$ & $(0.148)$ & $(0.149)$ & $(0.139)$ & $(0.134)$ & $(0.136)$ \\
\hline \multirow[t]{2}{*}{ Constant } & $62.735^{* * *}$ & $64.526^{* * *}$ & $60.804^{* * *}$ & $63.453^{* * *}$ & $63.462^{* * *}$ & $60.854^{* * *}$ \\
\hline & $(0.318)$ & $(0.359)$ & $(0.304)$ & $(0.405)$ & $(0.422)$ & $(0.386)$ \\
\hline
\end{tabular}

Standard errors in parentheses ${ }^{*} p<0.05,{ }^{* *} p<0.01,{ }^{* * *} p<0.001$ 
that each unit increase in the learning motivation scale is associated with 1.708 standardized points increase in Math, 1.180 increase in Chinese, and 1.992 increase in English. These results affirm the importance of student motivation in achieving higher academic outcomes.

Other control variables are significantly related with academic performance as well. Girls achieve higher test scores than boys do in all three subjects, in line with the common perception of female advantage among Chinese students (Liu 2018). Students who are migrants and singletons have higher academic performance in all three subjects than non-migrants and children with siblings. Living with both parents, having higher cognitive test scores, and effort in studying are also related to high performances. Finally, parent-teacher interactions are negatively related to children's test scores. However, this might be due to a selection effect, since parents of low performers might reach out to or are contacted by teachers more often than parents with high performing children.

\section{Conclusions}

This study considers the roles of family and teachers in shaping student learning. In doing so, we use nationally representative data in China to examine the relative importance of family background and student-teacher interaction in the classroom in shaping students' instrumental learning motivation. Our findings reveal some clear patterns. First, student learning motivations are significantly related to both family SES and teacher-student interaction. Second, and more importantly, our study points to important dynamics by showing a mediated relationship between family background and student motivation by student-teacher interaction. Third, we show that the observed relationships differ by academic subjects. For Chinese and Math, student-teacher interactions completely mediate the positive association between family background and student learning motivation. Conversely, for English, students from advantaged family backgrounds have higher levels of learning motivation than students from disadvantaged family backgrounds even after controlling for levels of student-teacher interaction. Fourth, we show that not only are advantaged students more likely to interact with teachers, the association between student-teacher interaction and student learning motivation is also greater for higher-SES students.

Our findings carry important implications for educational inequality in China. One implication concerns the role of teachers in the context of rapidly expanding inequality in education (Xie and Zhou 2014). Our findings show that student-teacher interaction in the classroom is positively correlated with learning motivation for students. In other words, teachers help enhance student motivation in general. However, this effect differs in magnitudes. The positive association between student-teacher interaction and student learning motivation is stronger for high-SES students than for low-SES students, suggesting that the observed association between student-teacher interaction and learning motivation works in favors of higher-SES. Furthermore, considering that teachers more often praise and direct questions to high-SES students compared to low-SES students in class, high-SES students likely enjoy a substantially more supportive classroom 
environment than low-SES students. Teacher-student interaction thus becomes a mechanism that reproduces inequality in Chinese classrooms. For teachers who create a highly supportive and interactive environment in classrooms in general, the increase in the SES-based gap in learning motivation could become an unintended consequence.

A second implication is the sustained class-based advantages by course subject. Our results suggest that educational inequality is particularly significant in student performance in English tests. Compared to Chinese and Math, student motivation in learning English is strongly associated with family background and this association cannot be fully explained by classroom interactions with teachers. Considering the significantly positive association between student learning motivation and their academic performance, this implies that English learning-both student motivation and the resulting academic performance-heavily reflects class-based privileges.

This paper has certain limitations. First, it is possible that learning motivations and student-teacher classroom interactions influence each other simultaneously. However, we do not argue for causality in the models, but instead try to reveal the associations between family background, student-teacher interactions, and student learning motivations. Future studies can make use of longitudinal data to scrutinize the potential causal relationship. Second, our focus on instrumental motivations also precludes the analysis of relationships between family, teachers, and students' intrinsic motivations to classroom learning. Using data from The Program for International Student Assessment (PISA), OECD (2013) reports that intrinsic motivations are especially important for Math performance. Future studies could incorporate both intrinsic as well as instrumental motivations to better examine student motivation and its relationship with family background and classroom interactions in various educational contexts. Finally, we choose to adopt a school-level fixed effect approach because it allows the comparison of within-school variation. One limitation of this modeling strategy is that the model does not account for peers or students' character-based assignments with teachers. Yet, if parents perform teacher-shopping, or if peers congregate in nonrandom patterns, there may be a larger upward bias in the estimates reported in this study.

Despite these limitations, we believe that the findings call attention to the role of teachers and family for a greater understanding of the reproduction of inequality through student experiences in the classroom. The fact that teachers may be unconsciously contributing to class-based inequality through classroom interactions that are intended to enhance student learning for all pupils may come as a surprise to many educators. Our study provides a picture of student motivations at a relatively young age-at seventh and ninth grades, before they go through exam selection into high school. The roles of teachers and family background might be different for students in high school. However, it is crucial for teachers to be aware of how their interactions with students, regardless of their intentions, have unintended consequences on classroom stratification based on student family backgrounds. After all, constructing a supportive and equal learning environment is critically dependent on teachers, whose interaction with students is so powerful that it even mitigates the role of family background in shaping student learning motivations. 


\section{Appendix}

Table 4 School fixed effect models predicting student-teacher interaction $(N=17,284)$

\begin{tabular}{|c|c|c|c|c|c|c|}
\hline & \multicolumn{3}{|l|}{ Model 1} & \multicolumn{3}{|l|}{ Model 2} \\
\hline & $\overline{\text { Math }}$ & Chinese & English & $\overline{\text { Math }}$ & Chinese & English \\
\hline \multirow[t]{2}{*}{ Family SES } & $0.322^{* * *}$ & $0.354^{* * *}$ & $0.371^{* * *}$ & $0.286^{* * *}$ & $0.330^{* * *}$ & $0.324^{* * *}$ \\
\hline & $(0.023)$ & $(0.023)$ & $(0.023)$ & $(0.024)$ & $(0.024)$ & $(0.024)$ \\
\hline \multirow[t]{2}{*}{ Female } & & & & $-0.157^{* * *}$ & 0.038 & $0.194^{* * *}$ \\
\hline & & & & $(0.024)$ & $(0.024)$ & $(0.024)$ \\
\hline \multirow[t]{2}{*}{ Migrant } & & & & 0.004 & 0.043 & 0.005 \\
\hline & & & & $(0.036)$ & $(0.036)$ & $(0.036)$ \\
\hline \multirow[t]{2}{*}{ Ethnic minority } & & & & 0.046 & -0.027 & 0.018 \\
\hline & & & & $(0.062)$ & $(0.061)$ & $(0.063)$ \\
\hline \multirow[t]{2}{*}{ Rural hukou } & & & & 0.045 & 0.054 & 0.004 \\
\hline & & & & $(0.030)$ & $(0.029)$ & $(0.030)$ \\
\hline \multirow[t]{2}{*}{ Only child } & & & & -0.050 & -0.041 & -0.058 \\
\hline & & & & $(0.029)$ & $(0.029)$ & $(0.030)$ \\
\hline \multirow[t]{2}{*}{ Coresidence with both parents } & & & & $0.084^{* *}$ & 0.047 & $0.073^{*}$ \\
\hline & & & & $(0.030)$ & $(0.029)$ & $(0.030)$ \\
\hline \multirow[t]{2}{*}{ Cognitive test score } & & & & $0.113^{* * *}$ & $0.032^{*}$ & $0.110^{* * *}$ \\
\hline & & & & $(0.016)$ & $(0.015)$ & $(0.016)$ \\
\hline \multirow[t]{2}{*}{ Student effort } & & & & $0.017^{* * *}$ & $0.016^{* * *}$ & $0.015^{* * *}$ \\
\hline & & & & $(0.003)$ & $(0.003)$ & $(0.003)$ \\
\hline \multirow[t]{2}{*}{ Parent-teacher interaction } & & & & $0.082^{* * *}$ & $0.083^{* * *}$ & $0.073^{* * *}$ \\
\hline & & & & $(0.007)$ & $(0.007)$ & $(0.007)$ \\
\hline \multirow[t]{2}{*}{ Ninth grade cohort } & $-0.342^{* * *}$ & $-0.222^{* * *}$ & $-0.402^{* * *}$ & $-0.367^{* * *}$ & $-0.249^{* * *}$ & $-0.433^{* * *}$ \\
\hline & $(0.024)$ & $(0.023)$ & $(0.024)$ & $(0.024)$ & $(0.023)$ & $(0.024)$ \\
\hline \multirow[t]{2}{*}{ Constant } & $5.198^{* * *}$ & $5.280^{* * *}$ & $5.393^{* * *}$ & $4.752^{* * *}$ & $4.763^{* * *}$ & $4.884^{* * *}$ \\
\hline & $(0.016)$ & $(0.016)$ & $(0.016)$ & $(0.053)$ & $(0.052)$ & $(0.053)$ \\
\hline
\end{tabular}

${ }^{*} p<0.05,{ }^{* *} p<0.01,{ }^{* *} p<0.001$

\section{Endnotes}

${ }^{1}$ All sensitivity analyses are available upon request.

${ }^{2}$ Some studies use cognitive ability to represent academic achievement (see for example Downey et al. 2007). However, the cognitive test CEPS administered did not measure Mathematics, Chinese, and English separately; thus, it was not the optimal choice of measurement for the purpose of this study.

${ }^{3}$ Hukou is the household registration system in mainland China, which officially identifies a person as a resident of a particular area.

${ }^{4}$ When predicting student motivation and student-teacher interaction, we also use a set of ordered logistic regression models as sensitivity tests. No significant difference has been found in estimated directions of effects and levels of significance. We report results from linear regression models for clearer interpretation.

${ }^{5}$ We also used structural equation models (SEM) for each set of analysis. The estimated directions of coefficients as well as levels of significance for each variable were similar to separate fixed effects models. 
Abbreviations

CEPS: China Education Panel Survey; PISA: The Program for International Student Assessment; SES: Socioeconomic status

\section{Acknowledgements}

We would like to thank Dr. Lukasz Czarnecki for inviting us to submit to this special issue.

\section{Funding}

The authors gratefully acknowledge funding support from the University of Pennsylvania's Judith and William Bollinger Graduate Fellowship to Ran Liu, and from the Ministry of Science and Technology in Taiwan (Grant No. 107-2410-H004-002) to Yi-Lin Chiang during the period of this study.

\section{Availability of data and materials}

The China Education Panel Survey data used in this paper can be accessed at https://ceps.ruc.edu.cn/

\section{Authors' contributions}

$\mathrm{RL}$ conducted the data analysis. RL and Y-LC contributed equally in shaping the research, analysis, and manuscript. Both authors read and approved the final manuscript.

\section{Competing interests}

The authors declare that they have no competing interests.

\section{Publisher's Note}

Springer Nature remains neutral with regard to jurisdictional claims in published maps and institutional affiliations.

\section{Author details}

${ }^{1}$ Department of Sociology, University of Pennsylvania, 3718 Locus Walk, Philadelphia, PA 19104, USA. ²Department of Sociology, National Chengchi University, Taipei, Taiwan.

Received: 26 November 2018 Accepted: 27 March 2019

Published online: 15 April 2019

\section{References}

Allison, Paul D. 2009. Fixed Effects Regression Models. Thousand Oaks: SAGE Publications.

Auwarter, Amy E., and Mara S. Aruguete. 2008. Effects of Student Gender and Socioeconomic Status on Teacher Perceptions. The Journal of Educational Research 101 (4): 242-246.

Brophy, Jere. 2013. Motivating Students to Learn. London: Routledge.

Brunello, Giorgio, and Daniele Checchi. 2007. Does School Tracking Affect Equality of Opportunity? New International Evidence. Economic Policy 22 (52): 782-861.

Calarco, Jessica Mccrory. 2011. "'I Need Help!' Social Class and Children's Help-Seeking in Elementary School". American Sociological Review 76(6): 862-882.

Cao, Yi-ming, and H.E. Chen. 2009. Research of the Type of Teacher-Student Interaction Behavior Subject in Junior Middle School Mathematics Classroom on the LPS Video Date. Journal of Mathematics Education 5: 14.

Chiang, Yi-Lin. 2018. "When Things Don't Go as Planned: Contingencies, Cultural Capital, and Parental Involvement for Elite University Admission in China." Comparative Education Review 62(4): 503-521.

Chirkov, Valery I., and Richard M. Ryan. 2001. Parent and Teacher Autonomy-Support in Russian and U.S. Adolescents: Common Effects on Well-Being and Academic Motivation. Journal of Cross Cultural Psychology 32 (5): 618-635.

Cohen, Elizabeth G., and Rachel A. Lotan. 1995. Producing Equal-Status Interaction in the Heterogeneous Classroom. American Educational Research Journal 32 (1): 99-120.

Cohen, Elizabeth G., Rachel A. Lotan, and Chaub Leechor. 1989. Can Classrooms Learn? Sociology of Education 62 (2): 75-94.

De Boer, Hester, Roel J. Bosker, and Margaretha P.C. van der Werf. 2010. Sustainability of Teacher Expectation Bias Effects on Long-Term Student Performance. Journal of Educational Psychology 102 (1): 168.

Diamond, John B., Antonia Randolph, and James P. Spillane. 2004. Teachers Expectations and Sense of Responsibility for Student Learning: The Importance of Race, Class, and Organizational Habitus. Anthropology and Education Quarterly 35 (1): 75-98.

DiMaggio, Paul. 1982. Cultural Capital and School Success: The Impact of Status Culture Participation on the Grades of U.S. High School Students. American Sociological Review 47 (2): 189-201.

Dumais, Susan A., and Aaryn Ward. 2010. Cultural Capital and First-Generation College Success. Poetics 38 (3): 245-265.

Eccles, Jacquelynne. 2009. Who Am I and What Am I Going to Do With My Life? Personal and Collective Identities as Motivators of Action. Educational Psychologist 44 (2): 78-89.

Eccles, Jacquelynne S. 2007. Families, Schools, and Developing Achievement-Related Motivations and Engagement. In Handbook of socialization: Theory and research, 665-691. New York: Guilford Press.

Eccles, Jacquelynne S., and Allan Wigfield. 2002. Motivational Beliefs, Values, and Goals. Annual Review of Psychology 53: 109-132. Entwisle, Doris R., and Karl L. Alexander. 1994. Winter Setback: The Racial Composition of Schools and Learning to Read. American Sociological Review 59 (3): 446-460.

Farkas, George, Robert P. Grobe, Daniel Sheehan, and Yuan Shuan. 1990. Cultural Resources and School Success: Gender, Ethnicity, and Poverty Groups within an Urban School District. American Sociological Review 55 (1): 127-142.

Farmer, Thomas W., Meghan McAuliffe Lines, and Jill V. Hamm. 2011. Revealing the Invisible Hand: The Role of Teachers in Children's Peer Experiences. Journal of Applied Developmental Psychology 32 (5): 247-256. 
Gaztambide-Fernandez, Rubén A. 2009. The Best of the Best: Becoming Elite at an American Boarding School. Cambridge, Mass: Harvard University Press.

Gonzalez-DeHass, Alyssa R., Patricia P. Willems, and Marie F. Doan Holbein. 2005. Examining the Relationship Between Parental Involvement and Student Motivation. Educational Psychology Review 17 (2): 99-123.

Grolnick, Wendy S., Rachel W. Friendly, and Valerie M. Bellas. 2009. Parenting and Children's motivation at school. In Handbook of Motivation at School, 279-300.

Heckman, James J. 2008. Schools, Skills, and Synapses. Economic Inquiry 46 (3): 289-324.

Heckman, James J. 2011. The American Family in Black \& White: A Post-Racial Strategy for Improving Skills to Promote Equality. Daedalus 140 (2): 70-89.

Henderson, Valanne L., and Carol S. Dweck. 1990. Motivation and Achievement. In At the Threshold: The Developing Adolescent, 308-329. Cambridge: Harvard University Press.

Ho, Phoebe and Hua-Yu Sebastian Cherng. 2018. "How Far Can the Apple Fall? Differences in Teacher Perceptions of Minority and Immigrant Parents and Their Impact on Academic Outcomes." Social Science Research 74: 132-145.

$\mathrm{Hu}$, Guangwei. 2008. The Misleading Academic Discourse on Chinese-English Bilingual Education in China. Review of Educational Research 78 (2): 195-231.

Hughes, Jan, and Oi-man Kwok. 2007. Influence of student-teacher and parent-teacher relationships on lower achieving readers' engagement and achievement in the primary grades. Journal of Educational Psychology 99 (1).

Jones, M. Gail, and Glenda Carter. 2007. Science Teacher Attitudes and Beliefs. In Handbook of research on science education, 1067-1104. New York: Routledge.

Jussim, Lee, and Kent D. Harber. 2005. Teacher Expectations and Self-Fulfilling Prophecies: Knowns and Unknowns, Resolved and Unresolved Controversies. Personality and Social Psychology Review 9 (2): 131-155.

Kipnis, Andrew B. 2011. Governing Educational Desire: Culture, Politics, and Schooling in China. Chicago: University of Chicago Press. Lareau, Annette. 2011. Unequal Childhoods. 2nd ed. Berkeley, CA: University of California Press.

Lin, Angel M.Y. 1999. Doing-English-lessons in the reproduction or transformation of social worlds? TESOL Quarterly 33 (3): 393-412.

Liu, Ran. 2018. Gender-Math Stereotype, Biased Self-Assessment, and Aspiration in STEM Careers: The Gender Gap among Early Adolescents in China. Comparative Education Review 62 (4): 522-541.

Lu, Yao, and Hao Zhou. 2013. Academic Achievement and Loneliness of Migrant Children in China: School Segregation and Segmented Assimilation. Comparative Education Review 57 (1): 85-116.

Marchant, Gregory J., Sharon E. Paulson, and Barbara A. Rothlisberg. 2001. Relations of Middle School Students Perceptions of Family and School Contexts with Academic Achievement. Psychology in the Schools 38 (6): 505-519.

Marcon, Rebecca A. 1999. Positive Relationships between Parent School Involvement and Public School Inner-City Preschoolers Development and Academic Performance. School Psychology Review 28 (3): 395.

Milner, Murray. 2015. Freaks, Geeks, and Cool Kids: Teenagers in an Era of Consumerism, Standardized Tests, and Social Media. New York: Routledge.

Mok, Ka Ho. 2015. Massification of higher education, graduate employment and social mobility in the Greater China region. British Journal of Sociology of Education 37 (1): 51-71.

Nonoyama-Tarumi, Yuko. 2008. Cross-National Estimates of the Effects of Family Background on Student Achievement: A Sensitivity Analysis. International Review of Education 54 (1): 57-82.

OECD. 2013. PISA 2012 Results: Ready to Learn: Students' Engagement, Drive and Self-Beliefs (Vol. III). Paris: PISA, OECD Publishing.

Pianta, Robert C., Bridget K. Hamre, and Joseph P. Allen. 2012. Teacher-Student Relationships and Engagement: Conceptualizing, Measuring, and Improving the Capacity of Classroom Interactions. In Handbook of research on student engagement, 365-386. Berlin: Springer.

Poston, Dudley L., and Toni Falbo. 1990. Academic Performance and Personality Traits of Chinese Children: 'Onlies' Versus Others. American Journal of Sociology 96 (2): 433-451.

Reimer, Michele S. 1996. 'Sinking into the Ground': The Development and Consequences of Shame in Adolescence. Developmental Review 16 (4): 321-363.

Rist, Ray. 1970. Student Social Class and Teacher Expectations: The Self-Fulfilling Prophecy in Ghetto Education. Harvard Education Review 40 (3): 411-451.

Ryan, Richard M., Jerome D. Stiller, and John H. Lynch. 1994. Representations of Relationships to Teachers, Parents, and Friends as Predictors of Academic Motivation and Self-Esteem. Journal of Early Adolescence 14 (2): 226-249.

Saracho, Olivia, and Bernard Spodek, eds. 2008. Contemporary Perspectives on Mathematics in Early Childhood Education. Charlotte, NC: Information Age Publishing.

Sewell, William H., Archibald O. Haller, and Alejandro Portes. 1969. The Educational and Early Occupational Attainment Process. American Sociological Review 34 (1): 82-92.

Shavit, Yossi, and Hans-Peter Blossfeld. 1993. Persistent Inequality: Changing Educational Attainment in Thirteen Countries. In Social inequality series. Boulder: Westview Press.

Skinner, Ellen A., and Michael J. Belmont. 1993. Motivation in the Classroom: Reciprocal Effects of Teacher Behavior and Student Engagement across the School Year. Journal of Education \& Psychology 85 (4): 571.

Tsui, Ming, and Lynne Rich. 2002. The Only Child and Educational Opportunity for Girls in Urban China. Gender and Society 16 (1): $74-92$.

Wang, Judy Huei-Yu, and John T. Guthrie. 2011. Modeling the Effects of Intrinsic Motivation, Extrinsic Motivation, Amount of Reading, and Past Reading Achievement on Text Comprehension between U.S. and Chinese Students. Reading Research Quarterly 39 (2): 162-186.

Wentzel, Kathryn R., Ann Battle, Shannon L. Russell, and Lisa B. Looney. 2010. Social Supports from Teachers and Peers as Predictors of Academic and Social Motivation. Contemporary Educational Psychology 35 (3): 193-202.

Wentzel, Kathryn R., Katherine Muenks, Daniel McNeish, and Shannon Russell. 1997. Peer and Teacher Supports in Relation to Motivation and Effort: A Multi-Level Study. Contemporary Educational Psychology 49: 32-45.

Xie, Yu, and Xiang Zhou. 2014. Income Inequality in Todays China. Proceedings of the National Academy of Sciences 111 (19): 6928-6933.

Yong, Zhao, and Keith P. Campbell. 1995. English in China. World Englishes 14 (3): 377-390.

Zhao, Qiran, Xiaohua Yu, Xiaobing Wang, and Thomas Glauben. 2014. The Impact of Parental Migration on Children's School Performance in Rural China. China Economic Review 31: 43-54. 